\title{
Surfactant Protein D Interacts with Pneumocystis carinii and Mediates Organism Adherence to Alveolar Macrophages
}

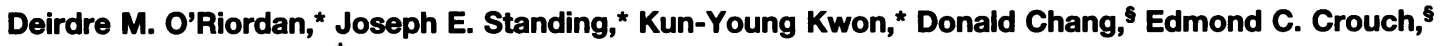 \\ and Andrew H. Limper*‡ \\ *Thoracic Diseases Research Unit, Division of Pulmonary, Critical Care and Internal Medicine and ${ }^{\ddagger}$ Department of Biochemistry and \\ Molecular Biology, Mayo Clinic and Foundation, Rochester, Minnesota 55905; and ${ }^{8}$ Department of Pathology, Jewish Hospital at \\ Washington University, St. Louis, Missouri 63110
}

\begin{abstract}
Pneumocystis carinii interacts with glycoproteins present in the lower respiratory tract through its mannose-rich surface antigen complex termed gpA. Surfactant protein D (SP-D) is a recently described component of the airspace lining material that possesses a calcium-dependent lectin domain capable of interacting with glycoconjugates present on microorganisms and leukocytes. Accordingly, we evaluated the extent and localization of SP-D in the lower respiratory tract during Pneumocystis pneumonia in an immunosuppressed rat model and examined its role in modulating interaction of $P$. carinii with macrophages. We report that SP-D is a major component of the alveolar exudates that typify $\boldsymbol{P}$. carinii pneumonia and is present bound to the surface of $P$. carinii organisms in vivo. We further demonstrate that SP-D binds to $P$. carinii through saccharide-mediated interactions with gpA present on the surface of the organism. Lastly, we show that SP-D augments binding of $P$. carinii to alveolar macrophages, but does not significantly enhance macrophage phagocytosis of the organism. The interaction of SP$D$ with gpA represents an additional important component of the host-parasite relationship during $P$. carinii pneumonia. (J. Clin. Invest. 1995. 95:2699-2710.) Key words: Pneumocystis carinii $\bullet$ surfactant protein D $\cdot$ gpA $\cdot$ macrophages - lectin
\end{abstract}

\section{Introduction}

Pneumocystis carinii pneumonia remains a common, life-threatening opportunistic infection in immunocompromised patients. It is particularly prevalent among those with acquired immunodeficiency syndrome (AIDS), hematologic or solid malignancies, transplanted organs, or in patients receiving chronic immunosuppressive therapies, particularly corticosteroids (1-6). $P$. carinii pneumonia is characterized by filling of the alveolar spaces with distinctive protein-rich foamy exudates laden with organisms (7). These proteinaceous exudates can be so marked as to mimic alveolar proteinosis (8). The exact chemical nature of the alveolar exudates in $P$. carinii pneumonia is not fully defined, but prior studies indicate the presence of fibronectin,

Address correspondence to Dr. Limper, Thoracic Diseases Research Unit, 601A Guggenheim Building, Mayo Clinic, Rochester, MN 55905. Phone: 507-284-2301; FAX: 507- 284-4521.

Received for publication 11 March 1994 and in revised form 15 February 1995.

The Journal of Clinical Investigation, Inc.

Volume 95, June 1995, 2699-2710 vitronectin, and surfactant components including surfactant protein D (SP-D) ${ }^{1}(8-13)$.

Alveolar macrophages play a significant role in host defense by binding, phagocytizing, and degrading $P$. carinii $(14,15)$. Recent investigations demonstrate that lung surfactant may participate in the host-organism relationship during $P$. carinii pneumonia and may modulate interaction of organisms with alveolar macrophages $(12,13,16,17)$. Surfactant protein-A (SP-A) is present in enhanced amounts in the lower respiratory tract during $P$. carinii pneumonia and binds to the organism $(12,17)$. Despite the presence of enhanced amounts of surfactant proteins in the lower respiratory tract during $P$. carinii pneumonia, physiologic studies suggest a relative deficiency of functional surface active material during pneumonia $(18,19)$.

SP-D is a collagenous protein synthesized and secreted by alveolar type II cells and nonciliated bronchiolar cells (20-23). Structural studies demonstrate that SP-D possesses a calciumdependent lectin-binding domain sharing high sequence homology with the group III mammalian C-type lectins (24-26). Several members of this family including bovine conglutinin, human mannose-binding protein, and SP-A are believed to participate in host defense against microorganisms (27-32). Previous studies indicate that SP-A binds to P. carinii and Staphylococcus aureus $(12,16,17,33)$. Furthermore, SP-A enhances phagocytosis of particles through $\mathrm{Fc}$ receptor and complement receptor-1 mechanisms (32). SP-D has also been shown to interact with lipopolysaccharide present on Escherichia coli and to mediate agglutination of the organism (34). Another C-type lectin, human mannose-binding protein, has been reported to function as an acute phase reactant and opsonin present in serum $(29,30)$. Additional studies indicate that SP-D interacts with leukocytes. In particular, recent studies demonstrate that SP-D binds to alveolar macrophages (23).

$P$. carinii possesses several carbohydrate-rich surface proteins capable of interacting with lectins and other glycoproteins (35-39). In particular, $P$. carinii contains a major surface glycoprotein complex which has been variously termed gpA, gp 95, gp120, or major surface glycoprotein (40-45). Differences in the relative molecular mass of this complex have been related to the host species from which the $P$. carinii are derived (35). Therefore, a number of investigators have adopted the nomenclature of gpA for this glycoprotein complex (44-47). Molecular studies indicate that gpA is encoded by a family of genes containing relatively conserved cysteine-rich regions $(41,42$, $45,46)$. N-linked carbohydrate rich in mannose, glucose, and $\mathrm{N}$-acetyl glucosamine residues represents approximately one-

1. Abbreviations used in this paper: $\mathrm{BAL}$, bronchoalveolar lavage; $\mathrm{gpA}$, the mannose-rich major surface glycoprotein complex of $P$. carinii; SPA, surfactant protein A; SP-D, surfactant protein D. 
tenth of gpA's mass $(35,36,48)$. gpA is known to interact with several glycoproteins including concanavalin A, fibronectin, and SP-A and likely represents a major ligand recognized during the interactions of $P$. carinii with alveolar epithelial cells and macrophages $(17,39,49,50)$. In view of the lectin-binding properties of SP-D and gpA, we hypothesized that SP-D interacts with $P$. carinii through binding of gpA present on the organism.

The current investigation was therefore undertaken to accomplish the following goals: $(a)$ to determine the extent and localization of SP-D in the lung during $P$. carinii pneumonia; (b) to investigate whether SP-D binds to $P$. carinii organisms in vivo and to determine which components of the organism interact with SP-D; and (c) to determine the effect of SP-D on the interaction of $P$. carinii with alveolar macrophages. We present evidence that SP-D is present in enhanced amounts in the lower respiratory tract during $P$. carinii pneumonia and that SP-D specifically binds to gpA and modulates interaction of the organism with alveolar macrophages.

\section{Methods}

Materials. All organic chemicals were obtained from Sigma Chemical Co. (St. Louis, MO) unless otherwise specified. ${ }^{125}$ I-Bolton-Hunter reagent was purchased from New England Nuclear (Boston, MA). A polyclonal rabbit antiserum generated against rat SP-D has been described previously (21). Monoclonal antibody 5E12, a mouse IgM recognizing gpA derived from rodent, human, and ferret, was the gift of Dr. Francis Gigliotti (Department of Pediatrics, University of Rochester, Rochester, NY) (51). A polyclonal goat antiserum recognizing macrophage mannose receptors was generously provided by Dr. Philip Stahl (Department of Cell Biology, Washington University, St. Louis, MO) (52).

Preparation of $P$. carinii. All studies described in this report were approved by the institutional animal care committee. $P$. carinii pneumonia was induced in Harlan Sprague-Dawley rats by immunosuppression with dexamethasone as reported previously $(53,54)$. Pathogen-free rats were provided with drinking water containing dexamethasone $(2 \mathrm{mg} /$ liter), tetracycline hydrochloride $(500 \mathrm{mg} / \mathrm{liter})$, and nystatin $(200,000$ U/liter). After $5 \mathrm{~d}$, rats were intratracheally inoculated with $P$. carinii (500,000 cysts) prepared by homogenizing lung from rats with pneumonia using a Stomacher blender (Tekmar Co., Cincinnati, OH). After 6 wk of additional immunosuppression, rats were killed, and whole lung lavage was performed with $50 \mathrm{ml}$ of either HBSS or TBS containing 1 $\mathrm{mM}$ calcium as specified. $P$. carinii organisms were purified from this lavage by differential centrifugation $(54,55)$. The recovered lavage fluids were initially centrifuged ( $400 \mathrm{~g}$ for $10 \mathrm{~min}$ ) to remove inflammatory cells. Some cysts were present in these initial cellular pellets, as identified by Diff-Quik staining (Baxter Healthcare Corp., Dade Division, McGraw, IL), and were discarded along with the inflammatory cells. The supernatants containing predominantly suspended $P$. carinii organisms were recentrifuged $(1,400 \mathrm{~g}$ for $30 \mathrm{~min})$. The pellets resulting from the second centrifugation represent the $P$. carinii isolates used in these studies. These isolates were resuspended in $1 \mathrm{ml}$ of HBSS, and duplicate 10-ml aliquots of this suspension were spotted onto glass slides, stained with Diff-Quick, and $P$. carinii quantified $(54,55)$. Prior studies in our laboratory revealed that these isolates contain both trophozoite and cyst forms in a ratio of 9:1 (55). P. carinii generally represented $>97 \%$ of the cellular material on Diff-Quik-stained smears with the remainder representing fragmented nonviable host cells. If other microorganisms were noted in the lavage smear, the material was discarded. Whole lung lavage from control rats without $P$. carinii failed to yield any material after the second centrifugation (54). Microbiologic cultures on selected $P$. carinii isolates demonstrated no growth of other bacteria or fungi over $72 \mathrm{~h}$.

Immunohistochemistry. Immunohistochemistry was performed to evaluate the distribution of SP-D present in rat lung during $P$. carinii pneumonia. Lung specimens were fixed in $10 \%$ phosphate-buffered formalin and embedded in paraffin. Serial 5- $\mu \mathrm{m}$ sections were deparaffinized with xylene and graded alcohols and submitted to either standard hematoxylin and eosin staining, immunohistochemistry, or methenamine silver staining to visualize cysts. Tissue localization of SP-D was evaluated using a polyclonal rabbit antibody generated against purified rat SP-D (21). The deparaffinized tissue sections were sequentially incubated for 30 min each in methanol containing $0.3 \%$ hydrogen peroxide to quench endogenous peroxidase activity, and $1.5 \%$ normal goat serum to reduce nonspecific binding of antibodies (56). Subsequently, the sections were incubated with primary antibody $(10 \mu \mathrm{g} / \mathrm{ml})$ for $4 \mathrm{~h}$. The sections were washed and reacted with biotinylated goat anti-rabbit IgG (2 $\mu \mathrm{g} / \mathrm{ml}$ for $30 \mathrm{~min}$; Dako Corp., Carpinteria, CA). The sections were next treated with peroxidase-conjugated streptavidin $(2 \mu \mathrm{g} / \mathrm{ml}$; Dako Corp.) for $30 \mathrm{~min}$, and bound antibodies detected with 3-amino9-ethylcarbazole substrate (AEC substrate; Dako Corp.) in the presence of $3 \%$ hydrogen peroxide for $15 \mathrm{~min}$. Sections were counterstained with hematoxylin. To confirm the specificity of staining, semiserial sections were incubated with nonimmune IgG, and identical lung regions were examined.

Immunoelectron microscopy. To directly evaluate whether SP-D was bound to the surface of both $P$. carinii cysts and trophozoites, immunoelectron microscopy was performed. $P$. carinii were isolated from bronchoalveolar lavage (BAL) of moribund rats using TBS with $1 \mathrm{mM}$ calcium to preserve surface-bound SP-D. Isolated organisms were fixed in periodate-lysine-paraformaldehyde buffer (57) and embedded in Lowacryl mounting medium (Ted Pella, Inc., Redding, CA). Ultrathin sections were obtained, blocked with normal goat serum (2\%) for $1 \mathrm{~h}$, and incubated with either rabbit anti-rat SP-D or nonimmune rabbit IgG (25 $\mu \mathrm{g} / \mathrm{ml})$ overnight. After washing, the sections were subsequently incubated with goat anti-rabbit IgG conjugated to $15 \mathrm{nM}$ colloidal gold (Amersham Corp., Arlington Heights, IL). The sections were washed again and examined on a transmission electron microscope (model 6400; JEOL USA Inc., Peabody, MA).

Detection of SP-D in cell-free BAL and on isolated P. carinii organisms. To determine the time course of SP-D accumulation during $P$. carinii pneumonia, rats were immunosuppressed and inoculated with $P$. carinii. Since corticosteroids are known to increase the expression of surfactant components in the lung, control rats were sham inoculated and maintained on an identical immunosuppressive regimen of dexamethasone. In addition, the corticosteroid-treated control animals also received trimethoprim, $160 \mathrm{mg} /$ liter, and sulfamethoxazole, $800 \mathrm{mg} /$ liter, added to the drinking water to prevent development of $P$. carinii pneumonia. At 2-wk intervals, rats from each group (four animals) were killed, lavaged with HBSS, and SP-D in the BAL assayed by immunoblotting. The first 5-ml aliquot of BAL from $P$. carinii-infected rats and from controls was centrifuged $(400 \mathrm{~g})$ to pellet cellular material. The supernatants were concentrated, dissolved in sample buffer, and separated by SDS-PAGE using 3\% stacking and 7\% resolving gels. Subsequently, the separated lavage proteins were transferred to nitrocellulose, and SP-D was detected by immunoblotting using anti-SP-D (1:1,000 dilution).

To similarly evaluate whether freshly isolated $P$. carinii possess surface bound SP-D, organisms were obtained from rats with fulminant $P$. carinii pneumonia by lavage with TBS containing $1 \mathrm{mM}$ calcium. The organisms were purified by differential centrifugation and washed in TBS with calcium. $P$. carinii were solubilized in $0.125 \mathrm{M}$ Tris, $4 \%$ SDS, and 4\% 2-mercaptoethanol and separated with SDS-PAGE and transferred to nitrocellulose. The membranes were washed with TBS containing $0.05 \%$ Tween 20 , and nonspecific binding sites were blocked with TBS containing $3 \%$ dried milk. The presence of organism-associated SP-D was assessed by immunoblotting using anti-SP-D (1:100 dilution). To investigate the saccharide and divalent cation dependency of SP-D's interaction with $P$. carinii, parallel experiments were performed where equal numbers of organisms were incubated for $30 \mathrm{~min}$ in either glucose $(100 \mathrm{mM})$, mannose $(100 \mathrm{mM})$, or EDTA $(20 \mathrm{mM})$ and washed before lysis and immunoblotting for SP-D. 
Purification and radiolabeling of SP-D. SP-D was isolated from the $10,000 \mathrm{~g}$ supernatant of lavage obtained from rats with silica-induced alveolar lipoproteinosis using affinity chromatography on maltosyl-agarose followed by gel filtration chromatography (58). Purity of the SP$D$ preparation was verified by SDS-PAGE and silver staining. Radioiodination of SP-D was undertaken by the method of Bolton and Hunter (59). In brief, benzene was removed from Bolton-Hunter iodination reagent by evaporation under a stream of nitrogen. SP-D (5-10 $\mu \mathrm{g})$ was added to $100 \mu \mathrm{l}$ of $0.1 \mathrm{M}$ sodium borate, $\mathrm{pH} 8.5$, in the presence of $2 \mathrm{mM}$ maltose and $2 \mathrm{mM}$ calcium chloride. This suspension was added to the dried Bolton-Hunter reagent and reacted for $2 \mathrm{~h}$ on ice, with agitation. Free iodine was removed by dialysis against $50 \mathrm{mM}$ Tris- $\mathrm{HCl}, \mathrm{pH}$ 7.4. The specific activity of the recovered protein was $\sim 2 \times 10^{6} \mathrm{cpm} / \mu \mathrm{g}$ protein.

Binding of $S P-D$ to separated $P$. carinii proteins. The interaction of SP-D with specific components of $P$. carinii was further assessed by evaluating binding of ${ }^{125} \mathrm{I}$-SP-D to solubilized $P$. carinii separated by SDS-PAGE and immobilized onto nitrocellulose. P. carinii $\left(20 \times 10^{6}\right.$ organisms), obtained by lavage with HBSS, were dissolved in $0.125 \mathrm{M}$ Tris, $4 \%$ SDS, $20 \%$ glycerol, and $4 \%$ 2-mercaptoethanol, separated by SDS-PAGE and transferred to nitrocellulose as described (55). The membranes were washed with TBS containing $0.05 \%$ Tween 20 and nonspecific binding sites blocked by incubation with TBS containing $1 \mathrm{mg} / \mathrm{ml} \mathrm{BSA}$ for $1 \mathrm{~h}$ at room temperature. Blocked membranes were incubated overnight in the same buffer containing $2 \times 10^{5} \mathrm{cpm}{ }^{125} \mathrm{I}$-SP$\mathrm{D} / \mathrm{ml}$. In some experiments, an identical number of $P$. carinii was blotted with ${ }^{125} \mathrm{I}-\mathrm{SP}-\mathrm{D}$ in the presence of EDTA $(20 \mathrm{mM})$ or glucose $(100 \mathrm{mM})$. The next day, membranes were extensively washed in TBS, and bound SP-D was visualized by autoradiography. To confirm the identity of $\mathrm{gpA}$ in the $P$. carinii extracts, immunoblotting was also performed with antibody 5E12, a mouse IgM monoclonal antibody which recognizes gpA (51). The nitrocellulose membranes were incubated with $\mathrm{mAb} 5 \mathrm{E} 12$ (1:50 dilution) or with a similar concentration of nonimmune control immunoglobulin, washed and reincubated with a secondary peroxidaseconjugated goat anti-mouse IgM antibody (Sigma Chemical Co.). Bound antibodies were visualized by reaction of peroxidase with diaminobenzidine in the presence of $\mathrm{H}_{2} \mathrm{O}_{2}$.

Interaction of purified $g p A$ with $S P-D$. Prior studies indicate that gpA can be purified from $P$. carinii using polyacrylamide gel electrophoresis $(11,39)$. $P$. carinii $\left(1 \times 10^{8}\right)$ were solubilized in $125 \mathrm{mM}$ Tris, $4 \%$ SDS, $4 \%$ 2-mercaptoethanol, $0.002 \%$ bromophenol blue, and $20 \%$ glycerol, pH 7.4. From this extract, gpA was purified by continuous flow electrophoresis over a $10 \%$ polyacrylamide preparative tube gel (PrepCell Apparatus; Bio-Rad Laboratories, Hercules, CA). The gel was resolved over $48 \mathrm{~h}$ using $25 \mathrm{~mA}$ current and continuously eluted with $25 \mathrm{mM}$ Tris Base, $192 \mathrm{mM}$ glycine, and $0.1 \%$ SDS. Fractions were analyzed by SDS-PAGE and silver staining on 4-15\% gradient resolving gels (Phast Gel System; Pharmacia LKB Biotechnology, Piscataway, $\mathrm{NJ})$. Fractions containing the $120-\mathrm{kD}$ complex were dialyzed and concentrated. Immunoblotting of the purified protein with monoclonal antibody $5 \mathrm{E} 12$ verified this material as gpA (51). To investigate SP-D binding to the purified gpA complex, we coated gpA (30 $\mu \mathrm{g} / \mathrm{ml}$ in 0.1 $\mathrm{M} \mathrm{NaHCO}_{3}$ ) on 96-well break apart ELISA plates (Removawell Plates; Dynatech Laboratories Inc., Chantilly, VA) for $8 \mathrm{~h}$ at $22^{\circ} \mathrm{C}$. The plates were washed and blocked by overnight incubation in TBS containing $1 \mathrm{mg} / \mathrm{ml} \mathrm{BSA}$ at $4^{\circ} \mathrm{C}$. The next day the plates were washed again and allowed to bind ${ }^{125}$ I-SP-D in TBS containing calcium $(1 \mathrm{mM})$ and BSA $(1 \mathrm{mg} / \mathrm{ml})$ at the indicated concentrations. To assess the effects of various sugar ligands on SP-D binding to gpA, additional incubations were performed in the presence of glucose, mannose, or lactose $(100 \mathrm{mM}$ each). Nonspecific binding was determined in parallel by the presence of $20 \mathrm{mM}$ EDTA which inhibited binding through SP-D's carbohydrate recognition domain.

Role of SP-D in P. carinii adherence to alveolar macrophages. We quantified the attachment of $P$. carinii to cultured alveolar macrophages in the presence or absence of antibody to SP-D or with the addition of purified SP-D. Adherence of $P$. carinii to alveolar macrophages was assayed by ${ }^{51} \mathrm{Cr}$-labeling the organisms $(60,61) . P$. carinii were isolated from rats with TBS containing $1 \mathrm{mM}$ calcium to prevent loss of surfacebound SP-D. The organisms were radiolabeled by incubation for $8 \mathrm{~h}$ at $37^{\circ} \mathrm{C}$ in $2 \mathrm{ml}$ of DME containing $20 \% \mathrm{FCS}$ and $200 \mu \mathrm{Ci}$ of ${ }^{51} \mathrm{Cr}$-sodium chromate (New England Nuclear). Normal alveolar macrophages were lavaged from healthy rats and plated in tissue culture plates $\left(1 \times 10^{5}\right.$ cells/well) which had been precoated with normal rat IgG $(100 \mu \mathrm{g} / \mathrm{ml}$ $\times 60 \mathrm{~min}$ ), in order to ensure firm adherence of the macrophages. After $1 \mathrm{~h}$, the macrophages were gently washed with HBSS to remove nonadherent cells. We have reported previously that $>95 \%$ of macrophages are adherent after this wash $(62) .{ }^{51} \mathrm{Cr}-P$. carinii $\left(1 \times 10^{6}\right)$ containing surface-associated SP-D were added to the macrophages and incubated at $37^{\circ} \mathrm{C}$ for an additional hour. Subsequently, nonadherent $P$. carinii were removed by washing. The macrophage monolayers containing adherent $P$. carinii were solubilized in $1 \mathrm{~N} \mathrm{NaOH}$ and quantified. Adherence of $P$. carinii was defined as: percentage of adherence $=(\mathrm{A} /$ $\mathrm{A}+\mathrm{B}) \times 100$, where $\mathrm{A}={ }^{51} \mathrm{Cr}-P$. carinii associated with the monolayer, and $\mathrm{B}=$ unattached ${ }^{51} \mathrm{Cr}-P$. carinii. To assess the effect of SP-D on the attachment of $P$. carinii to alveolar macrophage lung cells in culture, $P$. carinii adherence assays were conducted in the presence of nonimmune rabbit IgG $(100 \mu \mathrm{g} / \mathrm{ml})$, a polyclonal rabbit antibody generated against SP-D $(100 \mu \mathrm{g} / \mathrm{ml})$, or SP-D $(5 \mu \mathrm{g} / \mathrm{ml})$.

As a second method to evaluate SP-D-mediated binding of $P$. carinii to macrophages, we used specific sugars to dissociate SP-D from the surface of freshly isolated $P$. carinii. Interactions of SP-D with glycoconjugates are preferentially inhibited by maltose, but can also be inhibited by glucose and mannose, the principal sugar constituents of gpA $(9,22,34)$. In contrast, lactose is a much less effective inhibitor of SP-D interactions $(21,22,24)$. Accordingly, freshly isolated $P$. carinii were incubated with either maltose, mannose, or lactose $(100 \mathrm{mM})$ or in TBS containing $1 \mathrm{mM}$ calcium alone (control) for $1 \mathrm{~h}$. Subsequently, the organisms were washed and collected by centrifugation $(1,400 \mathrm{~g}$ $\times 5 \mathrm{~min}$ ). SP-D released into the supernatants was assessed with immunoblotting. The recovered organisms were additionally labeled with ${ }^{51} \mathrm{Cr}$ and assayed for their ability to adhere to alveolar macrophages.

Immunoprecipitation. Immunoprecipitation experiments were performed to determine whether the polyclonal antibody to SP-D might also crossreact with macrophage mannose receptors, another C-type lectin. Alveolar macrophages $\left(12 \times 10^{6}\right)$ were isolated from uninfected rats by lavage, starved in methionine-free RPMI medium containing $10 \%$ FBS for $1 \mathrm{~h}$, and incubated with ${ }^{35} \mathrm{~S}$-Trans label $(250 \mu \mathrm{Ci}$; New England Nuclear) in $5 \mathrm{ml}$ methionine-free RPMI containing $10 \%$ FBS overnight at $37^{\circ} \mathrm{C}$. The cells were washed, disrupted by repeated freezethaw cycles, and sonicated in $50 \mathrm{mM}$ Tris buffer (pH 7.4) containing $1 \mathrm{mM}$ leupeptin and $1 \mathrm{mM}$ pepstatin. Membrane-associated proteins were recovered by centrifugation at $100,000 \mathrm{~g}$ for $30 \mathrm{~min}$ and solubilized in PBS containing $1 \%$ Triton X-100 and $1 \mathrm{mM}$ calcium and magnesium. Radiolabeled macrophage protein extracts were divided into equal aliquots, preabsorbed with protein A-Sepharose, and parallel 50- $\mu \mathrm{l}$ aliquots were incubated with either anti-SP-D or with nonimmune rabbit IgG $(100 \mu \mathrm{g} / \mathrm{ml})$. Protein-antibody complexes were precipitated using protein $\mathrm{A}$-Sepharose, eluted with $1 \%$ SDS containing $5 \% \beta$-mercaptoethanol, and analyzed by SDS-PAGE as described previously (63). As a positive control, radiolabeled macrophage proteins were also immunoprecipitated using a polyclonal goat anti-mannose receptor antiserum, generously provided by Dr. Philip Stahl, or with nonimmune goat serum (52). For conditions using goat serum, protein G-Sepharose was substituted for protein A-Sepharose in an identical fashion.

Effect of SP-D on macrophage phagocytosis of $P$. carinii. To determine whether SP-D also mediates phagocytosis of $P$. carinii, radiolabeled $P$. carinii were allowed to bind to macrophages in the presence or absence of adenosine and homocysteine thiolactone, which are potent inhibitors of macrophage phagocytosis (64). P. carinii were radiolabeled with ${ }^{51} \mathrm{Cr}$ and incubated with alveolar macrophages for $2 \mathrm{~h}$ in the presence or absence of adenosine $(100 \mu \mathrm{M})$ and homocysteine thiolactone $(250 \mu \mathrm{M})$. Nonbound organisms were removed by washing, and the cells were lysed in $1 \mathrm{~N} \mathrm{NaOH}$ and quantified. The number of cpms associated with macrophages in the absence of inhibitors represents both bound and internalized $P$. carinii organisms. In contrast, the number of 
cpms associated with macrophages in the presence of adenosine and homocysteine thiolactone represents only bound $P$. carinii. The difference between these two determinations provides an estimate of phagocytosis. To evaluate the role of SP-D in binding and phagocytosis of $P$. carinii by macrophages, we compared the interaction of freshly isolated $P$. carinii, EDTA-treated organisms, and EDTA-treated $P$. carinii with additional SP-D. As an independent confirmation of the effectiveness of these agents in impairing phagocytosis, we and others have observed previously that adenosine and homocysteine thiolactone effectively inhibit the phagocytosis of opsonized zymosan particles by alveolar macrophages using the luminol-dependent chemiluminescence method (61).

Role of mannose receptors in $P$. carinii adherence to alveolar macrophages. To investigate the potential role of mannose receptors in mediating the SP-D-dependent adherence of $P$. carinii to alveolar macrophages, we further assayed $P$. carinii binding to macrophages in the presence of yeast $\alpha$-mannan. Yeast $\alpha$-mannan is an effective soluble inhibitor of macrophage mannose receptors $(65,66)$. Fresh untreated and EDTA-treated $P$. carinii were radiolabeled with ${ }^{51} \mathrm{Cr}$ as described. Alveolar macrophages were incubated with $\alpha$-mannan $(100 \mu \mathrm{g} / \mathrm{ml})$ for $20 \mathrm{~min}$ before the addition of radiolabeled ${ }^{51} \mathrm{Cr}$-labeled $P$. carinii with or without additional SP-D $(5 \mu \mathrm{g} / \mathrm{ml})$ and throughout a subsequent 60 min incubation. Unattached $P$. carinii were removed by washing, and the percentage of organisms adherent to the macrophage cell layers was determined by gamma counting.

Statistical methods. Data are expressed as mean \pm SEM from multiple experiments. Differences between multiple data groups were first assessed using one-way ANOVA. Subsequently, individual treatment groups were compared using $t$ tests with Bonferroni's correction for multiple comparisons. Differences between paired experimental data were assessed with Student's $t$ test for normal parameters and with the Mann-Whitney $U$ test for nonparametric data. Statistical testing was performed using Statview II package (Abacus Concepts, Inc., Berkeley, CA) on a Macintosh IIci computer, with $P<0.05$ defined as a significant difference.

\section{Results}

SP-D accumulates in the lung during $P$. carinii pneumonia. To determine whether SP-D participates in the pulmonary response to $P$. carinii, we evaluated the extent and tissue distribution of this surfactant-associated glycoprotein by immunohistochemistry using a rabbit polyclonal SP-D antibody (Fig. 1). Lung samples were obtained from rats with $P$. carinii pneumonia 68 wk after inoculation. Abundant immunoreactive SP-D was observed in the proteinaceous exudates filling the alveolar spaces. Additional staining was noted in bronchiolar and type II alveolar epithelial cells, and occasional cytoplasmic staining was also observed in macrophages. These exudates contained numerous $P$. carinii organisms as detected by silver staining. Examination of identical lung fields in semiserial sections with nonimmune IgG failed to demonstrate any staining, thereby confirming the specificity of the SP-D antibody. Immunostaining of normal rat lung with SP-D antibody revealed reactivity of bronchiolar and alveolar type II epithelial cells and occasional cytoplasmic staining of macrophages (67).

$S P-D$ is present on the surface of $P$. carinii. $P$. carinii exhibits a complex life cycle alternating between cystic forms and trophozoites (7). Accordingly, immunoelectron microscopy was performed to determine whether SP-D binds to the surface of these various $P$. carinii forms (Fig. 2). $P$. carinii were isolated from BAL performed with TBS containing $1 \mathrm{mM}$ calcium to preserve surface-bound SP-D. Polyclonal rabbit antibody to rat SP-D interacted specifically with the surface of $P$. carinii cysts, precysts, and trophozoites, thus indicating that SP-D is present on the surface of all forms of the organisms. Although immuno- electron microscopy is not rigorously quantitative, relative greater abundance of SP-D was found on the surface of $P$. carinii cysts compared with other forms. Parallel studies with nonimmune IgG exhibited no specific localization to either cysts or trophozoites.

$S P-D$ increases in BAL during the development of $P$. carinii pneumonia. We next sought to evaluate the time course over which SP-D accumulates during the development of pneumonia (Fig. 3). Rats were immunosuppressed with dexamethasone and inoculated with $P$. carinii. Since corticosteroid treatment itself is known to increase expression of surfactant components, control rats were also immunosuppressed with dexamethasone, but in addition received trimethoprim/sulfamethoxazole prophylaxis to prevent development of pneumonia. No control animals showed evidence of $P$. carinii pneumonia during the study. At 2-wk intervals, rats were killed, lavaged with HBSS, and soluble SP-D in the cell-free lavage supernatants was assessed by immunoblotting. The amounts of lavage fluid recovered were equivalent between $P$. carinii and control rats. Total BAL proteins are known to increase during the development of $P$. carinii pneumonia, likely reflecting alveolar capillary leak $(10,11)$. However, since SP-D is produced locally in the lung, any increase in total recoverable SP-D reflects enhanced local accumulation of this protein. Equal volumes of lavage fluid were recovered from control rats and animals with $P$. carinii and are therefore reflective of the total soluble SP-D present in the alveolar lining fluid (68). Accordingly, equal volumes of BAL from controls and animals with $P$. carinii ,were concentrated and analyzed by SDS-PAGE and immunoblotting. After 4 wk of immunosuppression, enhanced recoverable SP-D was seen in the rats with $P$. carinii pneumonia compared with controls (Fig. 3). Scanning densitometry of the immunoblots at the 4wk time point demonstrated a $170.4 \pm 17.1 \%$ increase in SP-D in rats with $P$. carinii pneumonia compared with controls ( $P$ $=0.05$ ). After $8 \mathrm{wk}$ of $P$. carinii pneumonia an $266.1 \pm 83.3 \%$ increase was observed $(P=0.04)$. It should be further noted that we measured soluble SP-D present in the lavage supernatant after a $400 \mathrm{~g}$ centrifugation. Even at these relatively low forces, a small amount of SP-D is lost in the cellular pellet. Therefore, the soluble SP-D determinations likely underestimate the total SP-D present in the lung. Nevertheless, we observed significant enhancement of the relative SP-D present in the rats with $P$. carinii pneumonia compared with the steroid-treated controls at these time points.

$S P-D$ interacts with $P$. carinii through saccharide-mediated mechanisms. To further determine the mechanisms by which SP-D interacts with $P$. carinii organisms, we next performed immunoblot analyses of whole organism extracts obtained from freshly purified $P$. carinii (Fig. 4). Organisms were obtained from rats by lavage in TBS containing $1 \mathrm{mM}$ calcium to preserve surface-bound SP-D. The organisms were lysed, and the proteins were separated by SDS-PAGE and blotted with antibody recognizing SP-D. Extracts from freshly isolated $P$. carinii contained abundant immunoreactive SP-D indicating that SP$\mathrm{D}$ is bound to these organisms in vivo (Fig. 4, lane $A$ ). Incubation of equal numbers of $P$. carinii with glucose, mannose, or EDTA before lysis and immunoblotting resulted in substantial removal of SP-D associated with the organisms. Incubation of $P$. carinii with glucose or mannose $(100 \mathrm{mM})$ as competing sugars removed 59 or $47 \%$ of the SP-D, respectively. EDTA $(20 \mathrm{mM})$ resulted in removal of $70 \%$ of the SP-D from $P$. carinii. Taken together, a significant fraction of SP-D's interac- 


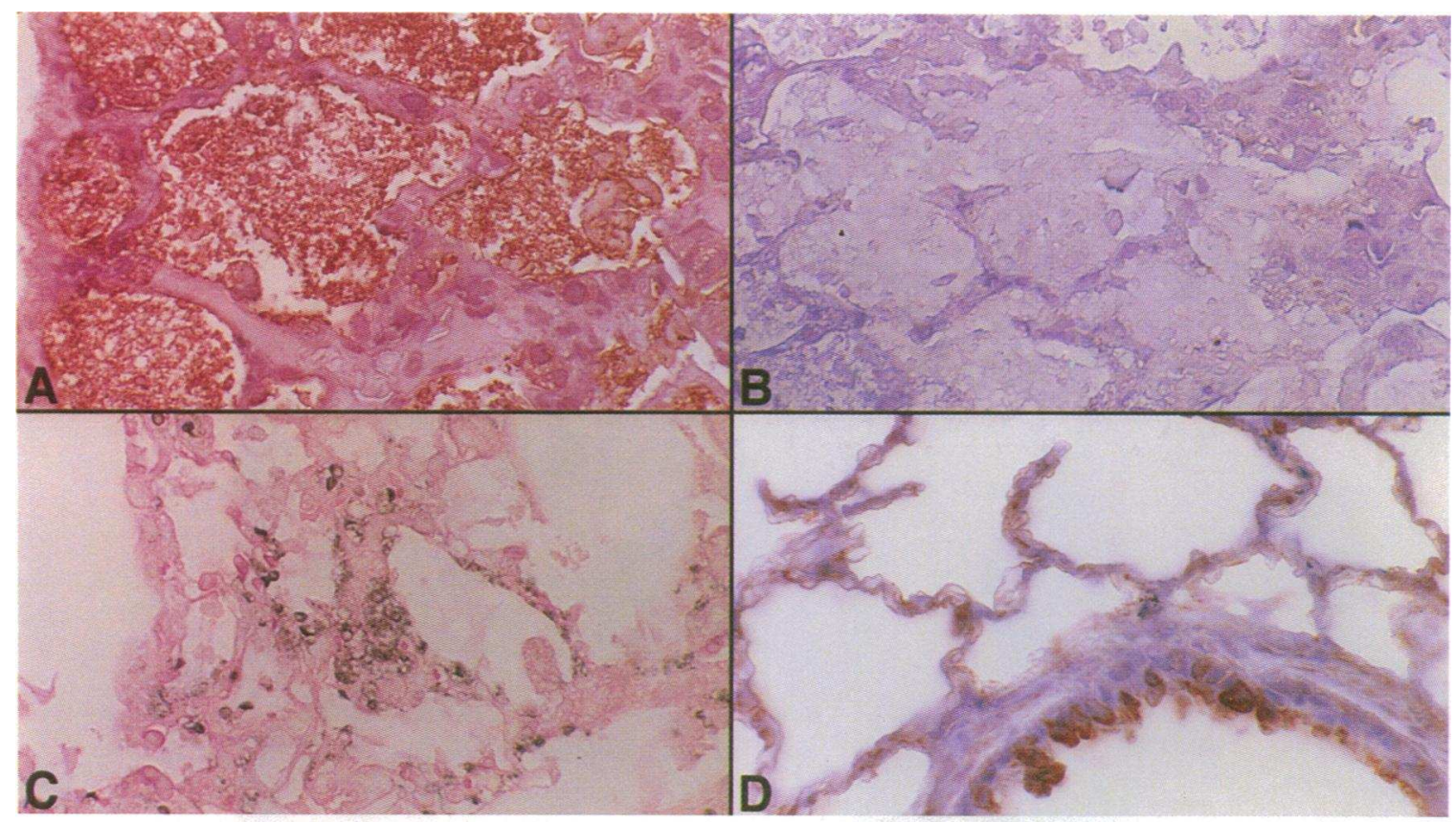

Figure 1. Immunohistochemical localization of SP-D during $P$. carinii pneumonia in the rat. $(A)$ Lung tissue obtained from rat with $P$. carinii pneumonia $8 \mathrm{wk}$ after inoculation. Marked immunoreactive SP-D (reddish-brown pigment) is observed in the proteinaceous exudates filling the alveolar spaces, as detected by a rabbit polyclonal SP-D antibody. $\times 1,000$. (B) Semiserial section of the identical lung field shows no reactivity of the intraalveolar exudates with nonimmune rabbit immunoglobulin verifying the specificity of the staining for SP-D. (C) Methenamine silver stain of this lung field demonstrates numerous $P$. carinii cysts. $(D)$ Staining of normal rat lung with the rabbit antibody recognizing SP-D reveals reactivity of bronchiolar epithelial cells and type II cells. $\times 1,000$.

tion with $P$. carinii is mediated by C-type lectin binding. It should be noted that a component of the SP-D associated with $P$. carinii was not displaceable by such manipulations. Similarly, prior studies by Lee et al. (69) indicate that the binding of other multimeric C-type lectins is not totally reversible with small competitive ligands.

$S P-D$ binds to gpA on ligand blot analysis. Next, lectin blot studies were performed to define which molecule(s) on the surface of $P$. carinii interacts with SP-D (Fig. 5). Purified $P$. carinii were extracted and separated by SDS-PAGE. Coomassie blue staining of $P$. carinii extracts demonstrated a prominent band migrating at $120 \mathrm{kD}$ with additional components between 40 and $70 \mathrm{kD}$. This $120-\mathrm{kD}$ band was identified as gpA by blotting with monoclonal antibody 5E12 which recognizes this major surface antigen of $P$. carinii (51). Incubating the membranes with ${ }^{125}$ I-SP-D demonstrated predominantly interaction of the surfactant protein primarily with gpA. Again, EDTA (20 $\mathrm{mM})$ and glucose $(100 \mathrm{mM})$ effectively inhibited the interaction of SP-D with the $120-\mathrm{kD}$ molecule during lectin blotting. These findings demonstrate that SP-D interacts with gpA present on $P$. carinii, through lectin-mediated binding.

Interaction of $S P-D$ with purified $g p A$. To further characterize the interaction of SP-D with gpA, the gpA glycoprotein complex was purified with preparative gel electrophoresis. ${ }^{125} \mathrm{I}-$ SP-D exhibited concentration-dependent binding to immobilized gpA (Fig. 6). The binding of SP-D to gpA was significantly inhibited by both glucose and mannose (100 mM each) $(P$ $<0.05$ compared with control). In contrast, lactose caused lesser inhibition in ${ }^{125} \mathrm{I}-\mathrm{SP}-\mathrm{D}$ binding to gpA. This pattern of sugar inhibition is consistent with the interaction of SP-D's carbohydrate recognition domain with carbohydrate moieties on gpA $(24,34,58)$. As a further confirmation of specificity, ${ }^{125} \mathrm{I}$ -
SP-D $(1 \mu \mathrm{g} / \mathrm{ml})$ binding to gpA immobilized on plastic was also studied in the presence of soluble gpA $(500 \mu \mathrm{g} / \mathrm{ml})$. The binding of ${ }^{125} \mathrm{I}-\mathrm{SP}-\mathrm{D}$ to immobilized gpA was inhibited $60 \pm 5 \%$ by the presence of soluble gpA $(P=0.003)$. Thus, soluble gpA can compete with immobilized ligand during this interaction.

$S P-D$ enhances the interaction of $P$. carinii with alveolar macrophages. After demonstrating that SP-D is bound to freshly isolated $P$. carinii, we next sought to determine whether SP-D modulates the adherence of $P$. carinii to macrophages (Fig. 7). Freshly isolated $P$. carinii possessing surface-associated SP-D were radiolabeled with ${ }^{51} \mathrm{Cr}$ and permitted to bind to alveolar macrophages in the presence of no added antibody, or with antibody to SP-D or nonimmune immunoglobulins. Incubation of the radiolabeled $P$. carinii with surface-associated SP-D in the presence of antibody recognizing SP-D resulted in significant reduction in $P$. carinii adherence to macrophages (asterisk in Fig. 7 denotes $P=0.0004$ compared with control). In contrast, incubation in the presence of nonimmune immunoglobulin did not alter adherence of the radiolabeled $P$. carinii to macrophages. To further confirm the specificity of the anti-SP-D antibody in these studies, parallel assays were performed in which $P$. carinii binding was evaluated in the presence of both anti-SP-D and purified SP-D $(5 \mu \mathrm{g} / \mathrm{ml})$ (Fig. 7). Addition of SP-D resulted in neutralization of the antibody, and $P$. carinii adherence was returned to control levels. Of interest, the addition of purified SP-D alone $(5 \mu \mathrm{g} / \mathrm{ml})$ resulted in little change in organism adherence to macrophages.

Since SP-D shares sequence homology with other C-type lectins, it is possible that the polyclonal antibodies recognizing SP-D may also crossreact with macrophage mannose receptors, another C-type lectin. Recent studies indicate that macrophage mannose receptors can mediate $P$. carinii uptake $(65,66)$. To 


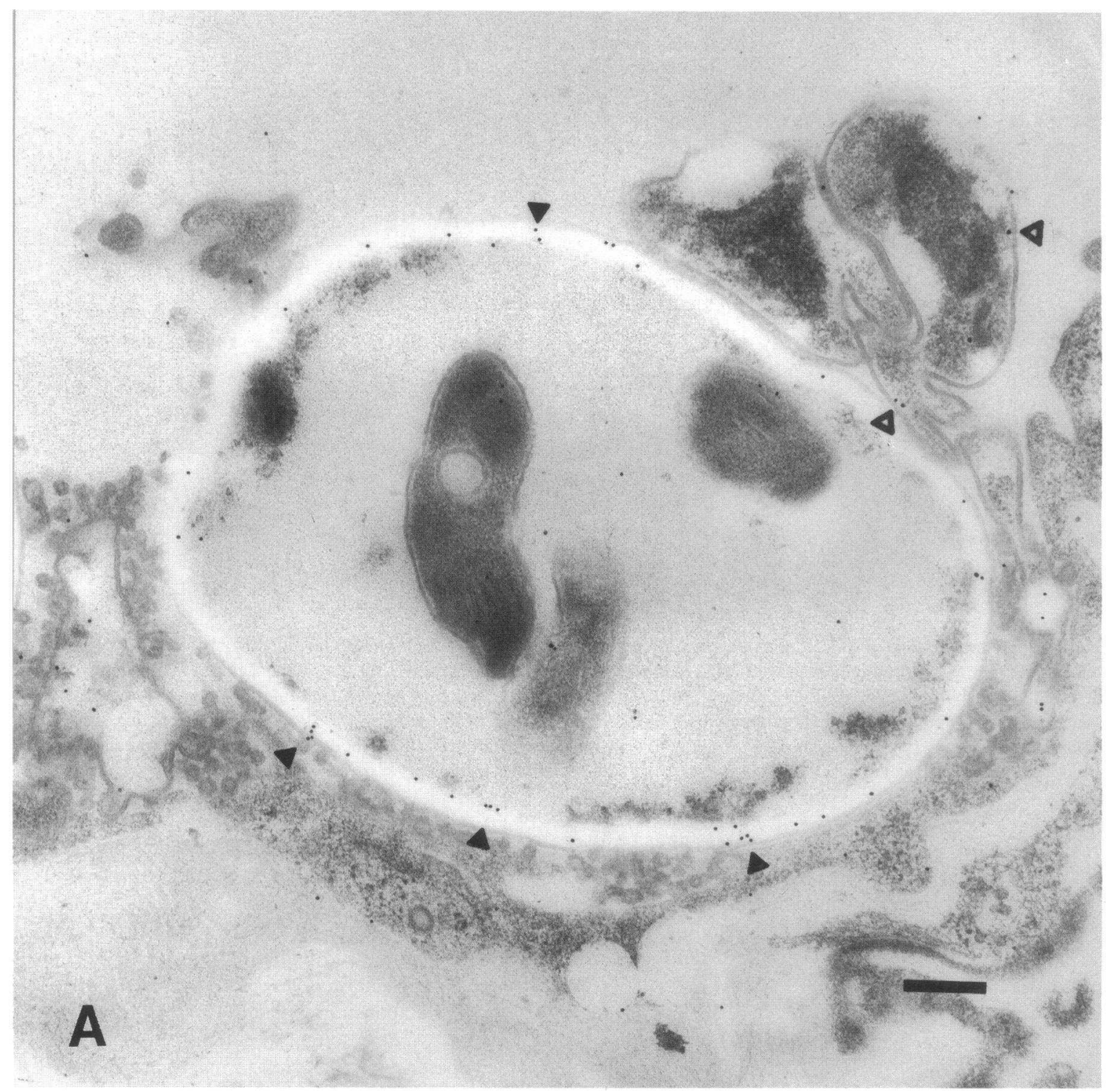

Figure 2. Immunoelectron microscopy reveals the presence of immunoreactive SP-D on the surface of $P$. carinii cysts and trophozoites. $(A) P$. carinii were isolated from infected rats by differential centrifugation from BAL with TBS containing $1 \mathrm{mM}$ calcium to preserve surface-bound SPD. Immunoelectron microscopy using a polyclonal antibody to rat SP-D reveals the presence of immunoreactive SP-D on the surface of $P$. carinii cysts as denoted by the solid arrows. In addition, an adjacent trophozoite also exhibits surface-bound SP-D as denoted by the hollow arrows. $\times 11,000$. (B) Immunoelectron microscopic localization of SP-D on the surface of a trophozoite form as well as an adjacent precystic form. $\times 8,600$. Bars, $1 \mu \mathrm{m}$. Incubation with nonimmune IgG failed to show any specific localization to either cysts or trophozoites (data not shown).

eliminate the possibility that the SP-D antibody might bind to macrophage mannose receptors and thereby prevent organism attachment through this mechanism, immunoprecipitation studies of radiolabeled macrophage proteins were undertaken (Fig. 8). We observed no crossreactivity of the SP-D antibody with the $165-\mathrm{kD}$ macrophage mannose receptor. A parallel immunoprecipitation performed with a polyclonal antiserum recognizing the macrophage mannose receptor precipitated an $165-\mathrm{kD}$ radiolabeled protein consistent with these receptors (52). Thus, the reduction in $P$. carinii adherence to macrophages mediated by the SP-D antibody was not caused by this antibody directly binding to mannose receptors.

To further study the effect of SP-D on $P$. carinii interaction to macrophages, specific sugars were used to dissociate SP-D already present on the organisms, and the resulting change in $P$. carinii adherence was measured (Fig. 9). The carbohydrate recognition domain of SP-D exhibits preferential recognition of maltose $(34,58)$. Consistent with this, maltose caused substantial dissociation of SP-D from the organisms. Maltose treatment also resulted in a significant decrease in organism adherence to macrophages $(P=0.02)$. Mannose, which represents the major sugar constituent of gpA, and a known competitor of SP-D binding, also dissociated SP-D from $P$. carinii and reduced organism binding to macrophages $(P=0.03)$. In contrast, lactose did not significantly dissociate SP-D from the organism and had little effect on $P$. carinii adherence. Thus, the specific removal of SP-D from the $P$. carinii is associated with reduction in $P$. carinii adherence to alveolar macrophages. 


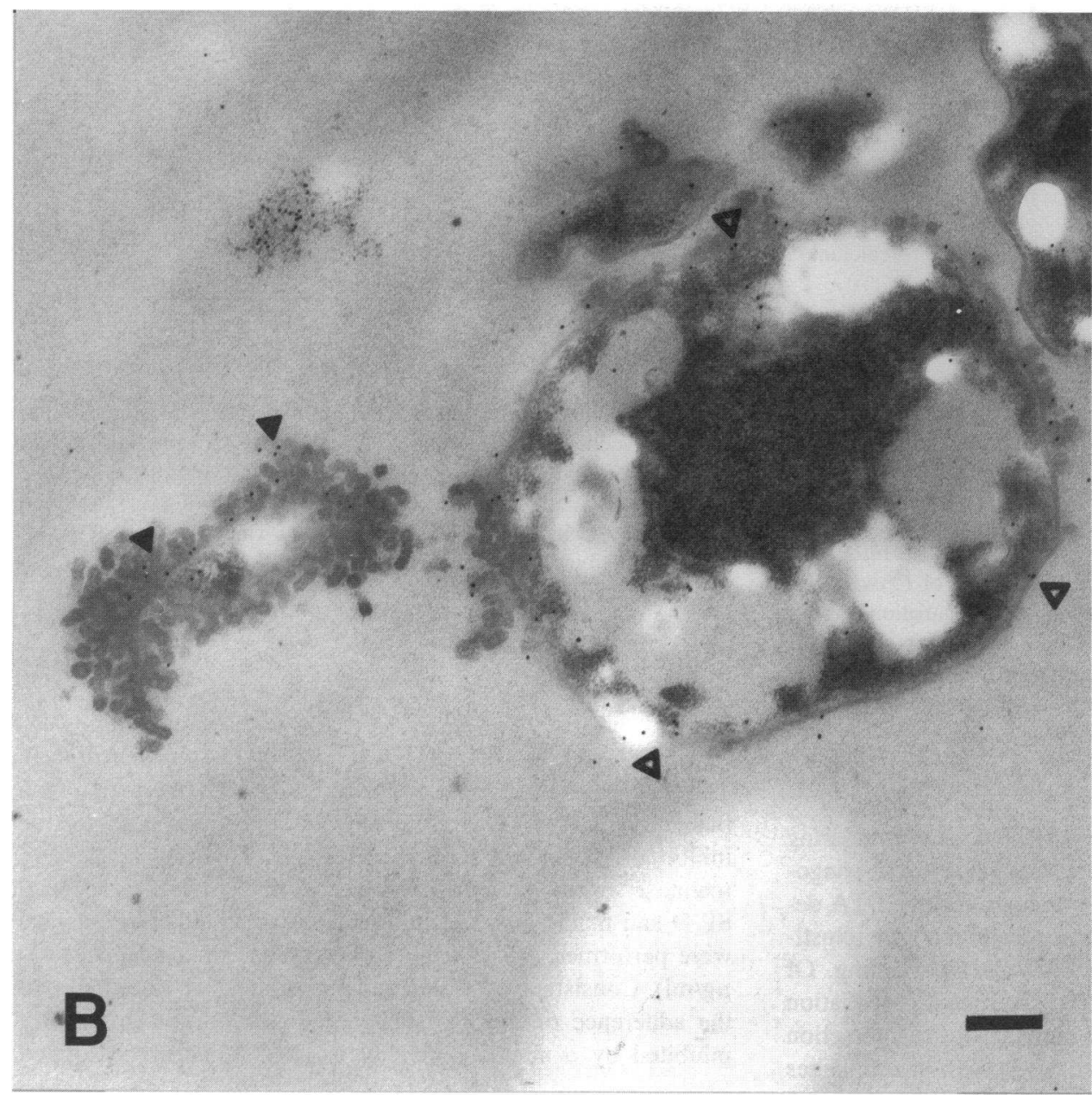

Figure 2 (Continued)

We further postulated that the reason that additional SP-D alone had minimal effect on the interaction of freshly isolated $P$. carinii with macrophages was likely related to the presence of SP-D already bound to the surface of the organisms (Figs. 2 and 3). To address this possibility, additional experiments were performed in which the $P$. carinii were first preincubated

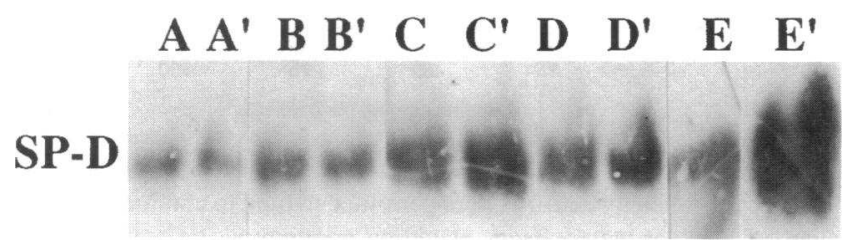

Figure 3. SP-D increases during the development of $P$. carinii pneumonia. Rats were immunosuppressed with dexamethasone and inoculated with $P$. carinii or received sham inoculation and immunosuppression with dexamethasone and trimethoprim/sulfamethoxazole prophylaxis (control). Lavage fluid was obtained, and soluble SP-D in the cell-free supernatant was assessed by immunoblotting. Lanes $A, B, C, D$, and $E$ represent SP-D immunoreactivity in control rats at weeks $0,2,4,6$, and 8, respectively. Lanes $A^{\prime}, B^{\prime}, C^{\prime}, D^{\prime}$, and $E^{\prime}$ represent SP-D immunoreactivity in rats with $P$. carinii at the identical time points. After 4 wk of immunosuppression, enhanced recoverable SP-D was seen in the rats with $P$. carinii pneumonia compared with controls. Shown are equal volumes of lavage at each time point, equally concentrated and resolved by SDS-PAGE and immunoblotting as described in Methods. with $20 \mathrm{mM}$ EDTA and washed before radiolabeling to remove as much surface-associated SP-D as possible (Fig. 10). In addition, EDTA treatment also removes other adhesive proteins including vitronectin, fibronectin, and SP-A from the organisms. Treatment of organisms with EDTA resulted in a significant reduction of the net binding of $P$. carinii to alveolar macrophages $(17.1 \pm 2.4 \%$ of unstripped controls; $P=0.0001$ compared with untreated controls). The addition of SP-D to EDTAtreated $P$. carinii caused a significant increase in organism adherence to macrophages $(52.1 \pm 6.1 \%$ of control; $P=0.001$ comparing adherent EDTA-treated organisms with and without SP-D). Taken together, these data strongly indicate that SP-D associated with $P$. carinii significantly augments binding of organisms to macrophages.

Role of $S P-D$ in $P$. carinii phagocytosis. Having observed that SP-D augments the interaction of $P$. carinii with macrophages, we next sought to determine whether SP-D functions as an opsonin. By definition, an opsonin enhances both the binding and phagocytosis of the organisms. To study this, we compared the interaction of macrophages with freshly isolated $P$. carinii, EDTA-treated organisms, and EDTA-treated $P$. carinii with added SP-D $(5 \mu \mathrm{g} / \mathrm{ml})$. Parallel studies were performed in the presence or absence of phagocytosis inhibitors (Fig. 10). We observed that freshly isolated $P$. carinii are both bound and phagocytized. Adenosine and homocysteine thiolactone significantly decreased the amount of radiolabeled $P$. carinii associated with macrophages, indicating $\sim 56.1 \pm 4.8 \%$ of organisms 


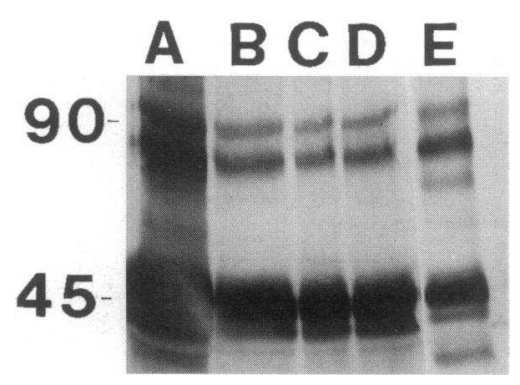

Figure 4. SP-D binds to $P$. carinii through saccharide-dependent mechanisms. (Lane A) P. carinii were isolated from rats by lavage and purified as described and washed once in TBS containing $1 \mathrm{mM}$ calcium. The organisms (10 $\times 10^{6}$ ) were lysed in $2 \%$ SDS with $4 \% \beta$-mercaptoethanol, separated with SDS-PAGE, transferred to nitrocellulose, and blotted with an antibody to SP-D (1:1,000 dilution). Freshly isolated $P$. carinii possess abundant immunoreactive SP-D bound to the surface of the organism. Monomeric SP-D migrates at $43 \mathrm{kD}$, the higher molecular mass bands represent dimeric SP-D $(\sim 90 \mathrm{kD})$ and higher molecular mass multimers. (Lane B) SP-D purified from silicotic rats (10 $\mathrm{ng}$ ) migrated in an identical fashion to the SP-D present on $P$. carinii. (Lane $C)$ SP-D was partially removed from an equal number of $P$. carinii by washing in glucose $(100 \mathrm{mM})$. (Lane $D)$ Similarly, incubation of an equal number of $P$. carinii with mannose $(100 \mathrm{mM})$ results in loss of SP-D from the organism. (Lane $E$ ) Incubation of an identical number of $P$. carinii with EDTA $(20 \mathrm{mM})$ resulted in substantial removal of SP-D from the organisms.

were phagocytized during these assays $(P=0.0003$ comparing freshly isolated $P$. carinii in the presence and absence of phagocytosis inhibitors). Treatment of the organisms with EDTA decreased $P$. carinii interaction with macrophages, and the reinstitution of SP-D significantly enhanced $P$. carinii binding. Of interest, however, SP-D did not result in significant potentiation of $P$. carinii phagocytosis $(P=0.07$ comparing the interaction of EDTA-treated $P$. carinii and added SP-D with macrophages in the presence and absence of inhibitors). These data indicate that, although SP-D promotes the binding of $P$. carinii to macrophages, it does not act as a potent opsonin for organism uptake.

Role of mannose receptors in $P$. carinii adherence to alveolar macrophages. Recent studies indicate that mannose recep-

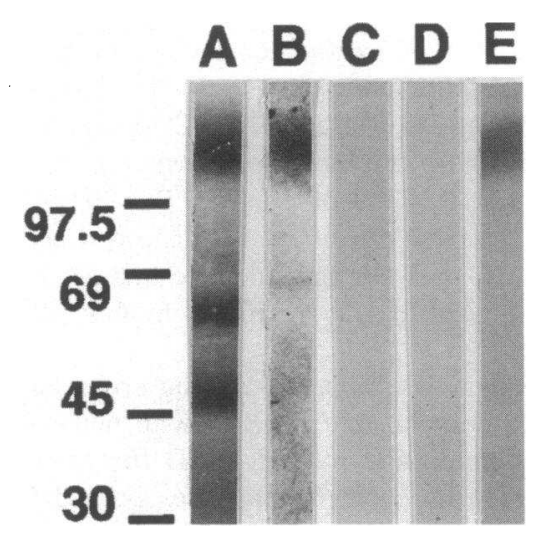

Figure 5. SP-D interacts with $P$. carinii gpA on ligand blot analysis. Purified $P$. carinii were extracted in $2 \%$ SDS containing $4 \% \beta$ -

mercaptoethanol, and the extracted components were separated by SDSPAGE and stained or transferred to nitrocellulose. (Lane A) Coomassie blue staining of the separated $P$. carinii extract demonstrates a prominent band at $120 \mathrm{kD}$. Ad-

ditional components between 40 and $70 \mathrm{kD}$ are also visible. (Lane B) Radiolabeled SP-D binds to the $120-\mathrm{kD}$ material, with minimal reactivity to other $P$. carinii components. (Lane $C$ ) EDTA $(20 \mathrm{mM})$ inhibits the interaction of SP-D with the 120-kD material. (Lane D) Glucose $(100 \mathrm{mM}$ ) inhibits SP-D binding to $P$. carinii components. (Lane $E$ ) Immunoblotting of $P$. carinii extracts with mAb 5E12 identifies the $120-\mathrm{kD}$ material as the major surface glycoprotein of $P$. carinii, termed gpA.

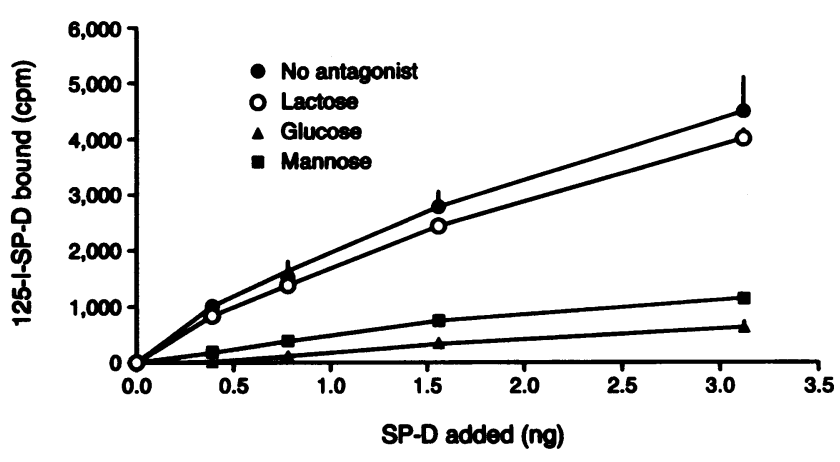

Figure 6. Radiolabeled SP-D binds to purified gpA. The mannose-rich surface glycoprotein complex of $P$. carinii known as gpA was purified by preparative polyacrylamide electrophoresis and solid-phase ligandbinding assays performed as described in Methods. ${ }^{125} \mathrm{I}-\mathrm{SP}-\mathrm{D}$ exhibited dose-dependent binding to immobilized gpA. This interaction was significantly inhibited by glucose and mannose. Lactose caused much less inhibition of binding. These findings are consistent with gpA binding to the carbohydrate recognition domain of SP-D. Shown are mean \pm SEM from three determinations.

tors participate in macrophage uptake of $P$. carinii $(65,66)$. These investigations demonstrate that $P$. carinii interaction with macrophages can be inhibited by yeast $\alpha$-mannan, a soluble inhibitor of mannose receptors $(65,66)$. To study the role of mannose receptors in the interactions of $P$. carinii-associated SP-D and macrophages, additional $P$. carinii adherence assays were performed in the presence or absence of $\alpha$-mannan (100 $\mu \mathrm{g} / \mathrm{ml})$. Consistent with our previous studies, we observed that the adherence of freshly isolated $P$. carinii was significantly inhibited by $\alpha$-mannan. Freshly isolated $P$. carinii exhibited

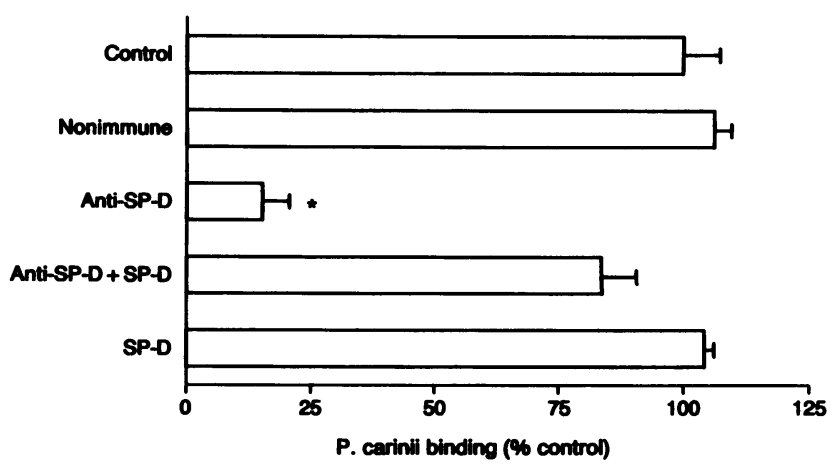

Figure 7. Role of SP-D in the adherence of $P$. carinii to alveolar macrophages. ${ }^{51} \mathrm{Cr}$-labeled $P$. carinii were permitted to bind to confluent monolayers of alveolar macrophages plated on nonimmune IgG over $1 \mathrm{~h}$ in DME containing BSA $(1 \mathrm{mg} / \mathrm{ml})$ in the presence of no additional SPD or antibody (Control) or in the presence of nonimmune IgG $(100 \mu \mathrm{g} /$ $\mathrm{ml})$ or with the polyclonal antibody recognizing SP-D $(100 \mu \mathrm{g} / \mathrm{ml})$. The specific antibody to SP-D but not the nonimmune IgG resulted in significant reduction in $P$. carinii adherence to macrophages $\left({ }^{*} P=0.0004\right.$ compared with control). To further assess the specificity of this antibody interaction in parallel assays, binding was studied in the presence of both anti-SP-D and purified SP-D $(5 \mu \mathrm{g} / \mathrm{ml})$. The addition of exogenous SP-D resulted in neutralization of the antibody, and $P$. carinii adherence was not significantly different from control. Interestingly, the addition of SP-D alone $(5 \mu \mathrm{g} / \mathrm{ml})$ resulted in little change in organism adherence to alveolar macrophages. Shown are the mean \pm SEM from six determinations. 


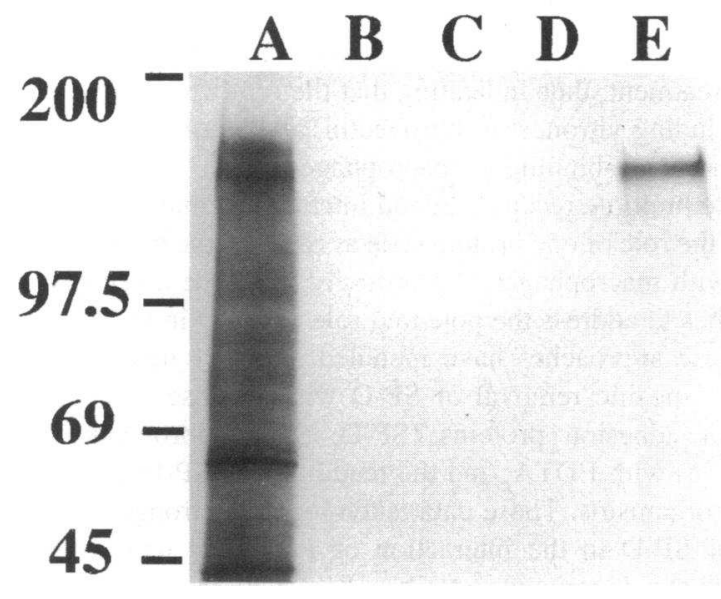

Figure 8. Immunoprecipitation verifies that the anti-SP-D antibody does not crossreact with macrophage mannose receptors. To determine whether the anti-SP-D antibody crossreacted with macrophage mannose receptors, another C-type lectin, immunoprecipitation studies were undertaken. Alveolar macrophages were isolated and radiolabeled as described in Methods. (Lane A) Total membrane-associated ${ }^{35} \mathrm{~S}$-labeled alveolar macrophage proteins. (Lane B) Nonimmune rabbit IgG (100 $\mu \mathrm{g} / \mathrm{ml}$ ) does not precipitate any macrophage proteins. (Lane $C$ ) Likewise treatment of the radiolabeled extracts with the SP-D antibody (100 $\mu \mathrm{g} /$ $\mathrm{ml}$ ) also did not immunoprecipitate any macrophage proteins. (Lane $D$ ) Nonimmune goat serum (1:100 dilution) also yielded no precipitation product. (Lane $E$ ) In contrast, a polyclonal goat antiserum recognizing macrophage mannose receptors (1:100 dilution) specifically precipitated a $165-\mathrm{kD}$ protein consistent with macrophage mannose receptors. Note specifically that the SP-D antibody (see lane $C$ ) did not crossreact with these $165-\mathrm{kD}$ macrophage mannose receptors.

$26.0 \pm 6.7 \%$ adherence in the presence of $\alpha$-mannan, compared with $100.0 \pm 5.4 \%$ maximal adherence in controls $(P=0.0001)$. We additionally observed that the residual adherence of EDTAstripped $P$. carinii was dramatically reduced by similar concentrations of $\alpha$-mannan. In these experiments, the adherence of

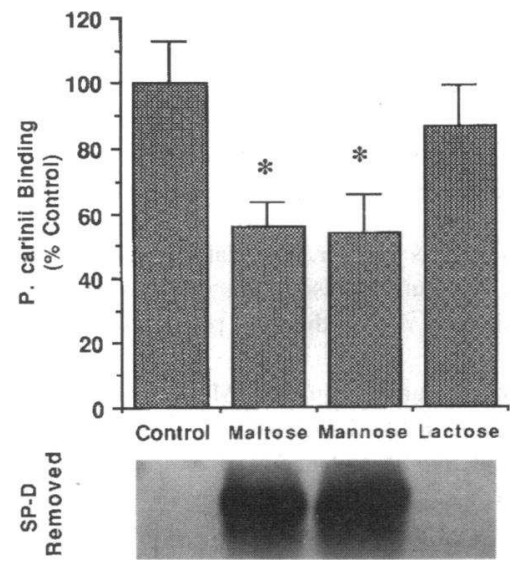

Figure 9. Removal of SP-D from $P$. carinii is associated with decreased organism adherence to macrophages. To further evaluate the role of SP-D in adherence of $P$. carinii to alveolar macrophages, freshly isolated organisms were incubated with specific sugar ligands to remove SP-D from the organisms. The adherence of treated organisms to alveolar macrophages was assayed. In parallel, SP-

$D$ released into the media was assessed by immunoblotting. Both maltose and mannose caused the release of SP-D from the organisms and significantly decreased adherence of $P$. carinii to macrophages. In contrast, treatment of $P$. carinii with lactose, which exhibits less interaction with SP-D, caused minimal release of SP-D and did not significantly alter $P$. carinii adherence to macrophages. Shown are mean \pm SEM from five determinations.

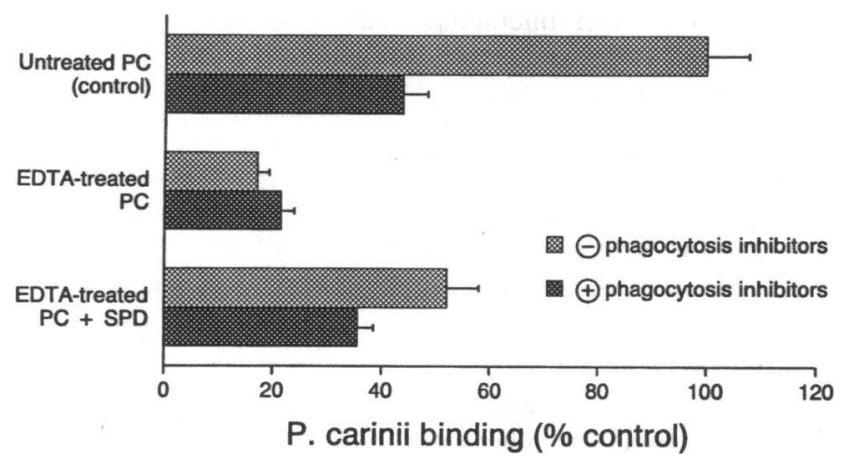

Figure 10. Role of SP-D in macrophage phagocytosis of $P$. carinii. To evaluate the potential role of SP-D in the binding and phagocytosis of $P$. carinii by macrophages, freshly isolated $P$. carinii were treated with EDTA to remove surface-associated adhesive proteins. The adherence of ${ }^{51} \mathrm{Cr}$-labeled EDTA-treated $P$. carinii was assessed in the presence or absence of SP-D $(5 \mu \mathrm{g} / \mathrm{ml})$ and in the presence or absence of the potent inhibitors of phagocytosis, adenosine $(100 \mu \mathrm{M})$ and homocysteine thiolactone $(250 \mu \mathrm{M})$. Treatment of $P$. carinii with EDTA significantly decreased organism interaction with macrophages. The subsequent addition of SP-D significantly enhanced $P$. carinii binding to macrophages. Interestingly, however, SP-D did not result in significant potentiation of organism phagocytosis. Shown are mean \pm SEM from five determinations.

EDTA-treated $P$. carinii to macrophages was reduced from $13.7 \pm 1.0$ to $5.3 \pm 1.0 \%$ by $\alpha$-mannan $(P=0.0002)$. Finally, we assessed whether mannose receptor inhibition would alter the SP-D-mediated adherence of $P$. carinii to macrophages. Although the adherence of EDTA-treated $P$. carinii with added SP-D $(5 \mu \mathrm{g} / \mathrm{ml})$ was somewhat reduced from $43.9 \pm 9.7$ to $29.4 \pm 9.0 \%$ by the presence of $\alpha$-mannan $(100 \mu \mathrm{g} / \mathrm{ml})$, this did not reach statistical significance $(P=0.33)$. These data confirm the previous findings by ourselves and others that mannose receptors do participate in $P$. carinii adherence to macrophages. However, our studies further indicate that mannose receptor inhibition does not significantly effect SP-D-mediated binding of $P$. carinii to alveolar macrophages.

\section{Discussion}

This investigation demonstrates that SP-D, a component of the airspace lining material, interacts with gpA, a mannose-rich glycoconjugate present on the surface of $P$. carinii. In addition, we demonstrated that enhanced quantities of SP-D are present in the lower respiratory during the development of $P$. carinii pneumonia and that SP-D is bound to the surface of freshly isolated $P$. carinii organisms. SP-D's interaction with $P$. carinii is inhibited by glucose, mannose, maltose, and EDTA, consistent with binding by the carbohydrate-recognition domain of SP-D. SP-D significantly participates in the adherence of $P$. carinii to alveolar macrophages. Removal of SP-D with EDTA or specific sugar inhibitors, or treatment of $P$. carinii with a polyclonal antibody to SP-D which recognizes epitopes in the carbohydrate recognition domain, significantly reduces $P$. carinii adherence to alveolar macrophages. Interestingly, although SP-D augments the binding of $P$. carinii to macrophages, SP$\mathrm{D}$ does not greatly enhance phagocytosis of the organism.

The presence of abundant SP-D in the lung during $P$. carinii pneumonia, coupled with the demonstration that this protein 
modulates organism interaction with macrophages, strongly suggests that SP-D accumulation may represent a significant element of the host-organism relationship during infection. As discussed, other C-type lectins including bovine conglutinin, human mannose-binding protein, and SP-A share structural similarities with SP-D and have been implicated previously in host recognition of infectious agents (28-33). SP-D and SP-A are present in the alveolar spaces and are known to interact with microorganisms and leukocytes. A greater understanding of these proteins and their interaction with microbes and host cells may provide further insights for prevention and treatment of $P$. carinii pneumonia and other infections of the lower respiratory tract.

The mechanisms of SP-D accumulation during $P$. carinii pneumonia are not yet understood. While it is possible that $P$. carinii infection may stimulate production of surfactant proteins, Rice and co-workers (70) have shown recently that $P$. carinii suppresses type II cell function in rats as measured by decreased secretion of surfactant phospholipid. Alternatively, $P$. carinii pneumonia may be associated with impairment of surfactant protein clearance. Our current investigation and prior work by Zimmerman et al. (17) indicate that $P$. carinii binds both SP-D and SP-A. It is possible that the organisms themselves act as a reservoir for the accumulation of surfactant proteins during pneumonia. Data concerning the abundance of SP$D$ during other pneumonias are not yet available. Recent studies suggest that although SP-A is increased during $P$. carinii pneumonia, SP-A is decreased in BAL during bacterial pneumonia $(12,71)$.

The interaction of $P$. carinii with alveolar macrophages is a complex interaction involving multiple receptor-ligand pairs. This study demonstrates that SP-D significantly augments adherence of $P$. carinii to macrophages but does not significantly promote phagocytosis in these assays. Inhibition of SP-D with specific antibodies or removal of SP-D from the organism significantly reduces the adherence of $P$. carinii to alveolar macrophages. Other investigations have shown that mannose receptors participate in macrophage uptake of the organism $(65,66)$. The ligands on $P$. carinii which are recognized by mannose receptors are not fully defined, but the mannose-rich surface glycoprotein gpA may itself represent one target molecule capable of interacting with mannose receptors $(50,63)$. Interestingly, however, the SP-D-mediated adherence of $P$. carinii to macrophages was not significantly inhibited by $\alpha$-mannan, suggesting that mannose receptors do not actively participate in this pathway of organism adherence to macrophages.

Additional studies reveal that other glycoproteins present in the lower respiratory tract also modulate the interaction of $P$. carinii with lung cells. In particular, the adhesive glycoprotein fibronectin has been implicated in $P$. carinii attachment to cultured lung epithelial cells and macrophages $(49,61)$. Interestingly, like SP-D, fibronectin enhances the attachment of $P$. carinii to alveolar macrophages, but does not augment phagocytosis of the organisms (61). Similarly, vitronectin also bind to $P$. carinii and mediates adherence of the organisms to lung epithelial cells (55). Both vitronectin and fibronectin are increased in the lower respiratory tract during $P$. carinii pneumonia $(10,11)$. To minimize the effect of other glycoproteins during $P$. carinii binding to macrophages, we treated the organisms with EDTA and assessed their ability to interact with macrophages in the presence of added SP-D. Under these conditions, SP-D significantly increased organism adherence to the macrophages. It should also be noted, however, that SP-D did not totally compensate for the reduction in organism binding resulting from EDTA treatment, thus indicating that the removal of other proteins including vitronectin, fibronectin, and SP-A may also decrease organism binding to macrophages.

These multiple receptor-ligand interactions make it difficult to study the role of one protein such as SP-D in the binding of $P$. carinii with macrophages. Accordingly, we have taken several approaches to address the potential role of SP-D in this interaction. These approaches have included antibody neutralization of SP-D, specific removal of SP-D with maltose, general removal of adhesion proteins (SP-D, SP-A, fibronectin, and vitronectin) with EDTA, and the readdition of SP-D to EDTAstripped organisms. These data taken together strongly support a role of SP-D in the interaction of $P$. carinii with alveolar macrophages. It remains possible, however, that some of reported effects of SP-D, such as the observed lack of effect of exogenous SP-D on the adherence of unstripped $P$. carinii to macrophages (Fig. 7), may also be related to the presence of other adhesive proteins on these freshly isolated organisms.

Some studies show that alveolar macrophages bind, phagocytize, and degrade $P$. carinii and are activated to release reactive oxidants, eicosanoids, and cytokines in response to the organism $(14,15,66-75)$. A number of potential mechanisms exist by which SP-D can increase binding without augmenting phagocytosis. For instance, SP-D may act to mask gpA on the surface of $P$. carinii, thus impairing phagocytosis through macrophage mannose receptors. In addition,-SP-D is known to aggregate microorganisms in vivo (34). Aggregates or clusters of organisms are characteristically observed in tissues and BAL obtained from patients with $P$. carinii pneumonia (7). While aggregation of $P$. carinii may promote adherence to epithelial surfaces or macrophages, large clusters of organisms may pose greater difficulty for phagocytosis and clearance.

In summary, our investigation demonstrates that SP-D, a surfactant-associated protein, is present in enhanced quantities in the lung during $P$. carinii pneumonia. SP-D binds to the mannose-rich antigen gpA present on the surface of the organism. Furthermore, the interaction of SP-D with $P$. carinii gpA modulates interaction of the organism with alveolar macrophages. Additional investigations will be required to fully determine the net benefit of SP-D for the organism and the host during $P$. carinii pneumonia.

\section{Acknowledgments}

The authors thank Dr. Ulrich Specks and Dr. Zvezdana Vuk-Pavlovic for many helpful discussions. The authors also appreciate the effort of Ms. Kathy Streich for her assistance during the final preparation of the manuscript.

This work was supported by funds from the Mayo Foundation, National Institutes of Health grants R29 AI 34336-01 (to A. H. Limper) and R01 HL-44015-04 (to E. C. Crouch), and an American Lung Association Research Grant (to A. H. Limper). These studies were performed during the tenure of an American Heart Association Clinician-Scientist Award (A. H. Limper).

\section{References}

1. Limper, A. H., K. P. Offord, T. F. Smith, and W. J. Martin. 1989. Pneumocystis carinii pneumonia: differences in lung parasite number and inflammation in patients with and without AIDS. Am. Rev. Respir. Dis. 140:1204-1209.

2. Cohn, D. L., D. E. Stover, R. F. O'Brien, J. H. Shelhamer, T. A. Raffin, 
and P. C. Hopewell. 1988. Pulmonary complications of AIDS: advances in diagnosis and treatment. Am. Rev. Respir. Dis. 135:1051-1052.

3. Murray, J. G., and J. Mills. 1990. Pulmonary infectious complications of human immunodeficiency virus infection. Am. Rev. Respir. Dis. 141:1582-1598.

4. Sepkowitz, K. A., A. E. Brown, E. E. Telzak, S. Gottlieb, and D. Armstrong. 1992. Pneumocystis carinii pneumonia among patients without AIDS in a cancer hospital. JAMA (J. Am. Med. Assoc.). 267:832-837.

5. Peters, S. G., and U. B. S. Prakash. 1987. Pneumocystis carinii pneumonia Am. J. Med. 82:73-78.

6. Centers for Disease Control. 1989. Guidelines for prophylaxis against Pneumocystis carinii pneumonia for persons with human immunodeficiency virus infection. MMWR (Morb. Mortal. Wkly. Rep.). 38:1-8.

7. Limper, A. H. 1991. Parasite adherence and host responses in the development of Pneumocystis carinii pneumonia. Sem. Respir. Infect. 6:19-26.

8. Tran Van Nheiu, J., A. M. Vojtek, J. F. Bernaudin, E. Escudier, and J. Fleury-Feith. 1990. Pulmonary alveolar proteinosis associated with Pneumocystis carinii. Ultrastructural identification in bronchoalveolar lavage in AIDS and immunocompromised non-AIDS patients. Chest. 98:801-805.

9. Crouch, E., A. Persson, and D. Chang. 1993. Accumulation of surfactant protein D in human pulmonary alveolar proteinosis. Am. J. Pathol. 142:241-248.

10. Neese, L. W., and A. H. Limper. 1993. Vitronectin is increased in the lower respiratory tract of patients with $P$. carinii pneumonia. Chest. 104:16S. (Abstr.)

11. Neese, L. W., J. E. Standing, E. J. Olson, M. Castro, A. H. Limper. 1994. The role of vitronectin, fibronectin, and immune opsonization in augmenting tumor necrosis factor- $\alpha$ release during Pneumocystis carinii pneumonia. J. Immunol. 152:4549-4556.

12. Phelps, D. S., and R. M. Rose. 1991. Increased recovery of surfactant protein A in AIDS-related pneumonia. Am. Rev. Respir. Dis. 143:1072-1075.

13. O'Riordan, D. M., J. E. Standing, E. C. Crouch, and A. H. Limper. 1993. Surfactant protein D interacts with Pneumocystis carinii. Am. Rev. Respir. Dis. 147:33a. (Abstr.)

14. Von Behren, L. A., and E. L. Pesanti. 1978. Uptake and degradation of Pneumocystis carinii by macrophages in vitro. Rev. Respir. Dis. 118:1051-1059.

15. Masur, H., and T. C. Jones. 1978. The interaction in vitro of Pneumocystis carinii with macrophages and L-cells. J. Exp. Med. 147:157-170.

16. Koziel, H., D. O'Riordan, D. Phelps, J. A. Fishman, M. Y. K. Armstrong, F. F. Richards, and R. M. Rose. 1992. Surfactant protein A inhibits binding and internalization of Pneumocystis carinii by alveolar macrophages. Am. Rev. Respir. Dis. 145:247a. (Abstr.)

17. Zimmerman, P. E., D. R. Voelker, F. X. McCormack, J. R. Paulsrud, and W. J. Martin.1992. 120-kD surface glycoprotein of Pneumocystis carinii is a ligand for surfactant protein A. J. Clin. Invest. 89:143-149.

18. Hoffman, A. G., M. G. Lawrence, F. P. Ognibene, A. F. Suffredini, G. Y. Lipschik, J. A. Kovacs, H. Masur, and J. H. Shelhamer. 1992. Reduction of pulmonary surfactant in patients with human immunodeficiency virus infection and Pneumocystis carinii pneumonia. Chest. 102:1730-1736.

19. Stokes, D. C., W. T. Hughes, P. O. Alderson, R. E. King, and D. J. Garfinkel. 1986. Lung mechanics, radiography and $67 \mathrm{Ga}$ scintigraphy in experimental Pneumocystis carinii pneumonia. Br. J. Exp. Pathol. 67:383-393.

20. Persson, A., K. Rust, D. Chang, M. Moxley, W. Longmore, and E. Crouch 1988. CP4: a pneumocyte-derived collagenous surfactant-associated protein. Evidence for heterogeneity of collagenous surfactant proteins. Biochemistry. 27:8576-8584.

21. Persson, A., D. Chang, K. Rust, M. Moxley, W. Longmore, and E. Crouch 1989. Purification and biochemical characterization of CP4 (SP-D): a collagenous surfactant-associated protein. Biochemistry. 27:6361-6367.

22. Persson, A., D. Chang, and E. Crouch. 1990. Surfactant protein D (SPD) is a divalent cation-dependent carbohydrate binding protein. J. Biol. Chem. 265:5755-5760.

23. Voorhout, W. F., T. Veenendaal, Y. Kuroki, Y. Ogasawara, L. M. vanGolde, and H. J. Geuze. 1992. Immunocytochemical localization of surfactant protein D (SP-D) in type II cells, Clara cells, and alveolar macrophages of rat lung. J. Histochem. Cytochem. 40:1589-1597.

24. Rust, R., L. Grosso, V. Zhang, D. Chang, A. Persson, W. Longmore, G. Kai, and E. Crouch. 1991. Human surfactant protein D: SP-D contains a C-type lectin carbohydrate recognition domain. Arch. Biochem. Biophys. 290:116-126.

25. Wiedemann, H., U. Holmskov, S. Theil, R. Timpl, and K. B. Reid. 1993. Structural similarity between lung surfactant protein $\mathrm{D}$ and conglutinin. Two distinct, C-type lectins containing collagen-like sequences. Eur. J. Biochem. 215:793-799.

26. Theil, S., and R. B. M. Reid. 1989: Structures and functions associated with the group of mammalian lectins containing collagen-like sequences. FEBS (Fed. Eur. Biochem. Soc.) Lett. 250:78-84.

27. Lee, Y. M., K. R. Leiby, J. Allar, K. Paris, B. Lerch, and T. B. Okarma 1991. Primary structure of bovine conglutinin, a member of the $C$ type animal lectin family. J. Biol. Chem. 266:2715-2723.

28. Friss-Christianson, P., S. Theil, S. E. Svehag, R. Dessau, P. Svendsen, O. Andersen, S. B. Laursen, and J. C. Jensenius. 1990. In vivo and in vitro antibacte- rial activity of conglutinin, a mammalian plasma lectin. Scand. J. Immunol. 31:453-460.

29. Ezekowitz, R. A., L. E. Day, and G. A. Herman. 1988. A human mannosebinding protein is an acute phase reactant that shares sequence homology with other vertebrate lectins. J. Exp. Med. 167:1034-1046.

30. Kuhlman, M., K. Joiner, and R. A. B. Ezekowitz. 1989. The human mannose-binding protein functions as an opsonin. J. Exp. Med. 169:1733-1745.

31. Iwarden, F. W., T. Kawasaki, and I. Yamashina. 1989. A serum lectin (mannan-binding protein) has complement dependent bactericidal activity. J. Biochem. (Tokyo). 106:483-489.

32. Tenner, A. J., S. L. Robinson, J. Borchelt, and J. R. Wright. 1989. Human pulmonary surfactant protein (SP-A), a protein structurally homologous to $\mathrm{Clg}$, can enhance FcR- and CR1-mediated phagocytosis. J. Biol. Chem. 264:1392313928.

33. McNeely, T. B., and J. D. Coonrod. 1993. Comparison of the opsonic activity of human surfactant protein A for Staphylococcus aureus and Streptococcus pneumonia with rabbit and human macrophages. J. Infect. Dis. 167:91-97.

34. Kuan, S. F., K. Rust, and E. Crouch. 1992. Interactions of surfactant protein D with bacterial lipopolysaccharides. Surfactant protein D is an Escherichia colibinding protein in bronchoalveolar lavage. J. Clin. Invest. 90:97-106.

35. Linke, M. J., M. T. Cushion, and P. D. Walzer. 1989. Properties of the major antigens of rat and human Pneumocystis carinii. Infect. Immun. 57:15471555 .

36. Radding, J. A., M. Y. K. Armstrong, E. Ullu, and F. F. Richards. 1989. Identification and isolation of a major cell surface glycoprotein of Pneumocystis carinii. Infect. Immun. 57:2149-2157.

37. Pesanti, E. L, and J. D. Shanley. 1988. Glycoproteins of Pneumocystis carinii: characterization by electrophoresis and microscopy. J. Infect. Dis. 158:1353-1359.

38. Lundgren, B., G. Y. Lipchik, and J. A. Kovacs. 1991. Purification and characterization of a major human Pneumocystis carinii surface antigen. J. Clin. Invest. 87:163-170.

39. Limper, A. H., S. T. Pottratz, and W. J. Martin. 1991. Modulation of Pneumocystis carinii adherence to cultured lung cells by a mannose-dependent mechanism. J. Lab. Clin. Med. 118:492-499.

40. Theus, S. A., M. J. Linke, R. P. Andrews, and P. D. Walzer. 1993. Proliferative and cytokine responses to a major surface glycoprotein of Pneumocystis carinii. Infect. Immun. 61:4703-4709.

41. Wada, M., K. Kitada, M. Saito, K. Egawa, and Y. Nakamura. 1993. cDNA sequence diversity and genomic clusters of major surface glycoprotein genes of Pneumocystis carinii. J. Infect. Dis. 168:979-985.

42. Kovacs, J. A., F. Powell, J. C. Edman, B. Lundgren, A. Martinez, B. Drew, and C. W. Angus. 1993. Multiple genes encode the major surface glycoprotein of Pneumocystis carinii. J. Biol. Chem. 268:6034-6040.

43. Gigliotti, F. 1992. Host species-specific variation of a mannosylated surface glycoprotein of Pneumocystis carinii. J. Infect. Dis. 165:329-336.

44. Haidaris P. J., T. W. Wright, F. Gigliotti, and C. G. Haidaris. 1992. Expression and characterization of a cDNA clone encoding an immunodominant surface glycoprotein of Pneumocystis carinii. J. Infect. Dis. 166:1113-1123.

45. Wright, T. W., P. J. Simpson-Haidaris, F. Gigliotti, A. G. Harmsen, and C. G. Haidaris. 1994. Conserved sequence homology of cysteine-rich regions in genes encoding glycoprotein A in Pneumocystis carinii derived from different host species. Infect. Immun. 62:1513-1519.

46. Stringer, S. L., T. Garbe, S. M. Suskin, and J. R. Stringer. 1993. Genes encoding antigenic surface glycoproteins in Pneumocystis carinii in humans, $J$. Eukaryotic Microbiol. 40:821-826.

47. Gigliotti, F., P. J. Haidaris, C. G. Haidaris, T. W. Wright, and K. R. Van der Meid. 1993. Further evidence of host species-specific variation in antigens of Pneumocystis carinii using the polymerase chain reaction. J. Infect. Dis. 168:191194.

48. Lundgren, B., G. Y. Lipchik, and J. A. Kovacs. 1991. Purification and characterization of a major human Pneumocystis carinii surface antigen. J. Clin. Invest. $87: 163-170$

49. Pottratz, S. T., J. Paulsrud, J. Smith, and W. J. Martin. 1991. Pneumocystis carinii attachment to cultured lung cells by gp120, a fibronectin binding protein. J. Clin. Invest. 88:403-407.

50. Limper, A. H., D. M. O'Riordan, and J. E. Standing. 1993. Pneumocystis carinii gp120 mediates organism attachment to alveolar macrophages but not release of tumor necrosis factor- $\alpha$. Clin. Res. 41:680a. (Abstr.)

51. Gigliotti, F., D. C. Stokes, A. B. Cheatham, D. S. Davis, and W. T. Hughes. 1986. Development of murine monoclonal antibodies to Pneumocystis carinii. J. Infect. Dis. 154:315-322.

52. Kery, V., J. J. Krepinsky, C. D. Warren, P. Capek, and P. D. Stahl. 1992. Ligand recognition of purified human mannose receptor. Arch. Biochem. Biophys. 298:49-55.

53. Bartlett, M. S., J. A. Fishman, S. A. Queener, M. M. Durkin, M. A. Jay, and J. W. Smith. 1988. New rat model of Pneumocystis carinii pneumonia. J. Clin. Microbiol. 26:1100-1102.

54. Limper, A. H., and W. J. Martin. 1990. Pneumocystis carinii: Inhibition of lung cell growth mediated by parasite attachment. J. Clin. Invest. 85:391-396. 
55. Limper, A. H., J. E. Standing, O. A. Hoffman, M. Castro, and L. W. Neese. 1993. Vitronectin binds to Pneumocystis carinii and mediates organism attachment to cultured lung epithelial cells. Infect. Immun. 61:4302-4309.

56. Limper, A. H., T. V. Colby, M. S. Sanders, S. Asakura, P. C. Roche, and R. A. DeRemee. 1994. Immunohistochemical localization of transforming growth factor- $\beta 1$ in the non-necrotizing granulomas of pulmonary sarcoidosis. Am. J. Respir. Crit. Care Med. 149:197-204.

57. McClean, I. W., and P. K. Nakane. 1974. Periodate-lysine-paraformaldehyde fixative. A new fixation for immunoelectron microscopy. J. Histochem. Cytochem. 22:1077-1083.

58. Crouch, E. C., A. Persson, D. Chang, and D. Parghi. 1991. Surfactant protein D (SP-D): increased accumulation in silica-induced lipoproteinosis. Am. J. Pathol. 139:765-776.

59. Bolton, A. E., and W. M. Hunter. 1973. The labeling of proteins to high specific radioactivities by conjugation to a 125 -I-containing acylating agent. Biochem. J. 133:529-539.

60. Pottratz, S. T., and W. J. Martin. 1990. Role of fibronectin in Pneumocystis carinii attachment to cultured lung cells. J. Clin. Invest. 85:351-356.

61. Pottratz, S. T., and W. J. Martin. 1990. Mechanism of Pneumocystis carinii attachment to cultured rat alveolar macrophages. J. Clin. Invest. 86:1678-1683.

62. Castro, M., T. I. Morgenthaler, O. A. Hoffman, J. E. Standing, M. S. Rohrbach, and A. H. Limper. 1993. Pneumocystis carinii induces the release of arachidonic acid and its metabolites from alveolar macrophages. Am. J. Respir. Cell Mol. Biol. 9:73-81.

63. O'Riordan, D. M., J. E. Standing, and A. H. Limper. 1995. Pneumocystis carinii glycoprotein A binds macrophage mannose receptors. Infect. Immun. 63:779-784.

64. Sung, S. S. J., and S. C. Silverstein. 1985. Inhibition of macrophage phagocytosis by methylation inhibitors. J. Biol. Chem. 260:546-554.

65. Ezekowitz, R. A. B., D. J. Williams, H. Koziel, M. Y. K. Armstrong, A. Warner, F. F. Richards, and R. M. Rose. 1991. Uptake of Pneumocystis carinii mediated by the macrophage mannose receptor. Nature (Lond.). 351:155-158.
66. Hoffman, O. A., J. E. Standing, and A. H. Limper. 1993. Pneumocystis carinii stimulates tumor necrosis factor- $\alpha$ release from alveolar macrophages through a $\beta$-glucan-mediated mechanism. J. Immunol. 150:3932-3940.

67. Crouch, E., D. Parghi, S. F. Kuan, and A. Persson. 1992. Surfactan protein D: subcellular localization in nonciliated bronchiolar epithelial cells. Am. J. Physiol. 263:L60-L66.

68. Limper, A. H., U. Specks, M. W. Brutinel, W. J. Martin II, and M. S. Rohrbach. 1993. Interlobar variations in the recovery of bronchoalveolar lavage fluid, cell populations, and angiotensin converting enzyme. J. Lab. Clin. Med. 121:785-791.

69. Lee, R. T., Y. Ichikawa, T. Kowasaki, K. Drickamer, and Y. C. Lee. 1992. Multivalent ligand binding by serum mannose-binding protein. Arch. Biochem. Biophys. 298:129-136.

70. Rice, W. R., F. M. Singelton, M. J. Linke, and P. D. Walzer. 1993. Regulation of surfactant phosphatidylcholine secretion from alveolar type II cells during Pneumocystis carinii pneumonia in the rat. J. Clin. Invest. 92:2778-2782.

71. Baughman, R. P., R. I. Sternberg, W. Hull, J. A. Buchsbaum, and J. Whitsett. 1993. Decreased surfactant protein A in patients with bacterial pneumonia. Am. Rev. Respir. Dis. 147:653-657.

72. Hidalgo, H. A., R. J. Helmke, V. F. German, and J. A. Mangos. 1992. Pneumocystis carinii induces an oxidative burst in alveolar macrophages. Infect. Immun. 60:1-7.

73. Krishnan, V. L., A. Meager, D. M. Mitchell, and A. J. Pinching. 1990. Alveolar macrophages in AIDS patients: increased spontaneous tumour necrosis factor-alpha production in Pneumocystis carinii pneumonia. Clin. Exp. Immunol. 80:156-160.

74. Chen, W., E. A. Havell, and A. G. Harmsen. 1992. Importance of tumor necrosis factor-alpha and gamma interferon in host resistance against Pneumocystis carinii infection. Infect. Immun. 60:1279-1284.

75. Kolls, J. K., J. M. Beck, S. Nelson, W. A. Summer, and J. Shellito. 1993. Alveolar macrophage release of tumor necrosis factor-alpha during murine Pneumocystis carinii pneumonia. Am. J. Respir. Cell Mol. Biol. 8:370-376. 